International Institute for Applied Systems Analysis - A-2361 Laxenburg - Austria Tel: +432236807 • Fax: +43223671313 • E-mail: info@iiasa.ac.at •Web: www.iiasa.ac.at

INTERIM REPORT IR-99-4/February

\title{
Analysis and Forecasting of Social Sec unity: A Study of Robustness
}

Anders Westlund (staw@hhs.se)

Tatiana Ermolieva (ermol@iiasa.ac.at)

Landis MacKellar (mckellar@iiasa.ac.at)

\section{Approved by}

Gordon J. Mac Donald (macdon@ilasa.ac .at)

Director

Interim Reports on work of the International Institute for Applied Systems Analysis receive only limited review. Views or opinions expressed herein do not necessarily represent those of the Institute, its National Member Organizations, or other organizations supporting the work. 


\section{Contents}

1. Introduction 1

1.1. The nature of social security 1

1.2. The IIASA model 2

1.3. Purpose and organization of this paper 2

2. The model 3

3. Robustness studies: numerical experiments 6

$\begin{array}{ll}\text { 3.1. Some robustness issues } & 6\end{array}$

3.2. Generation of uncertainties 6

3.3. Numerical results 8

4. Conclusions 17

5. References 18

Annex 1: The life-cycle dynamics of capital accumulation 19

$\begin{array}{ll}\text { Private Pension System (PvtPenSys) } & 19\end{array}$

Other asset classes (KOthFinIns, KRes, KPvtUnincorpEnt) 20

$\begin{array}{ll}\text { Accounting consistency check } & 21\end{array}$

Annex 2: The Public Pension System (PubPenSys) 24

$\begin{array}{ll}\text { Expenditures } & 24\end{array}$

$\begin{array}{ll}\text { Revenues } & 26\end{array}$ 


\section{Abstract}

In this paper, we analyze the robustness of an economic-demographic projection model emphasizing the macroeconomic impact of age-structured savings and consumption behavior. The parameters varied are saving and labor force participation rates (two of the key sources of uncertainty in the social security policy debate) and the parameters of the production function (the key source of uncertainty in any long-run economic analysis). The sensitivity analysis focuses on three variables: assets of the private pension system, the income of the non-working elderly, and the balance of the public Pay As You Go Pension system. 


\section{About the Authors}

Anders Westlund is visiting professor of statistics at the University of Economics, Vienna, on leave from the Stockholm School of Economics, where he is chair of the Statistics Department. His participation in the IIASA Social Security Reform (SSR) Project was made possible by the financial support of the Swedish Council for Planning and Coordination of Research (FRN). Tatiana Ermolieva is Research Assistant, and Landis MacKellar is Leader of the SSR Project. 


\title{
Analysis and Forecasting of Social Sec unity: A Study of Robustness
}

\author{
Anders Westlund \\ Tatiana Ermolieva \\ Landis MacKellar
}

\section{Introduction}

With population aging now rapidly underway, the future of social security regimes -- the broad spectrum of institutions, public and private, which provide for income in old age -- is being questioned (OECD, 1998; World Bank, 1994). Long-term projections and simulation analyses of pension system revenues and expenditures, stocks of private pension savings, etc., play a large role in the policy debate. In this paper, we report on the robustness analysis of a model designed for such applications.

\subsection{The nature of soc ial sec unity}

The main purpose of formal social security systems is to reduce the impact of contingencies associated with old age. The most important such contingency is reduction in the capacity to engage in remunerated work. Two main institutional mechanisms have arisen to cope with the need for income in old age. One, which dates from the end of the $19^{\text {th }}$ century, is the public defined-benefit pension system, which in most countries is funded on a Pay As You Go (PAYG) basis. "Defined benefit" means that the pension entitlement is determined relative to some benchmark, sometimes the worker's last salary, sometimes average lifetime earnings, etc. PAYG means that today's workers are taxed to fund today's pensioners, the implicit contract being that tomorrow's workers will similarly make transfers to tomorrow's retirees. In a classic defined-benefit PAYG pension system (such as Germany's), system liabilities are determined on an annual or quarterly basis as a function of the number of beneficiaries and their pension entitlements, then the required payroll tax rate is calculated. The second institutional arrangement is the private or public, defined-contribution pension system. "Defined contribution" means that the worker gets out simply what s/he puts in, plus accumulated capital returns. The institution of public defined contribution pension systems to replace or supplement downsized public PAYG systems is the 
central element of pension reforms now being implemented in many parts of the world (James, 1998). The Chilean system is the most commonly cited example.

Some combination of the two pension mechanisms, one based on transfers and the other on accumulation, can be used to describe pension arrangements in virtually every country. For example, in some countries (such as the United States) the PAYG public pension system is "partially funded," meaning that a capital reserve capable of meeting part of the system's liabilities is maintained. In many countries, such as Japan, large corporations offer partially-funded PAYG pension schemes to their long-term employees, but these schemes are, in effect, guaranteed by the government. Individual retirement saving accounts, which are popular in some countries, are conceptually identical to private defined-contribution pension schemes described above. Intrafamily transfers, which provide old-age support for most of the population in less developed countries, are simply a variant on the PAYG theme.

As evidenced by the current policy debate in most countries, social security is an ideological field. The debate is made more intense by the fact that each of the major institutional arrangements offers its own set of advantages and disadvantages. For example, defined-contribution systems may increase national savings, while definedbenefit systems may be more suited to targeted income redistribution. The stakes are high. Life-cycle saving and dissaving, which at the national level must include the social security system component of the government budget, stand in close relation to capital formation and economic growth. Public savings are often effectively the only source of income for the majority of the elderly. Somewhat surprisingly, the models applied to problems of social security and pension fund management have been almost exclusively purely actuarial in nature, that is, they contain no economic linkages. The IIASA research project is, in part, an effort to fill this gap.

\subsection{The IIASA model}

IIASA has developed a model to study long-run capital accumulation and economic growth as functions of the evolving age distribution of the population and the nature of the pension system. In view of the long-term nature of the social security problem, special emphasis has been given to dealing with uncertainty aspects. The uncertainty inherent to the long-term analysis of social security systems arises from a number of sources, among them, uncertainty in demographic projections, household saving rates and labor force participation rates. As in any long-term analysis, possible changes in the production function, i.e. technological change, are of special concern.

\subsection{Pupose and organization of this paper}

The goal of the model robustness analyses presented here is two-fold. On one hand, we would like to find the most "sensitive" components of the model with respect to the assumptions, explore the magnitude of responses to various types of uncertainties, and identify the main contributors to the variations (i.e., when slightly different parameter specifications lead to significant changes in the outcomes). On the other hand, explicit introduction of uncertainties allows us to better comprehend the diversity 
of possible responses and to approach the design of policies robust against the natural variability of the system. For example, explicit introduction of exogenous uncertainties may allow us to analyze the likelihood of financial distress for various arrangements of pension funds.

In this paper, we analyze the robustness of model solutions with respect to initial parameter assumptions and consider the cases of parameter time invariance, i.e. robustness of the model towards changing parameters. The parameters varied are saving and labor force participation rates (two of the key sources of uncertainty in the social security policy debate) and the parameters of the production function (the key source of uncertainty in any long-run economic analysis). The sensitivity analysis focuses on three variables of particular interest in the social security debate. These are:

- Assets of the private pension system. Since the work of Schieber and Shoven (1994), concern has been expressed that the retirement of the Baby Boom generation will give rise to "asset meltdown" as net flows into the private pension system switch from positive to negative.

- Relative income of retirees. The pension debate contains a large intergenerational equity component. While wealth variables are also relevant, relative income is a fairly good welfare index.

- Deficit of the public PAYG pension system. In a classic PAYG system, there is no deficit because the payroll tax is calculated to ensure balance. In the real world, raising payroll taxes is politically difficult, as is allowing pensioners' benefits to erode. As a result, pension-system deficits must often be covered out of general government revenue. The specter of widening pension-system deficits has been the principal motivation for recent policy research in the area (Roseveare et al., 1996).

The organization of the paper is as follows. Section 2 contains a cursory description of the model. Section 3 presents the robustness analysis. Subsection 3.1 contains some theoretical issues on robustness. Subsection 3.2 defines the uncertainties incorporated in these studies. In subsection 3.3 we describe numerical results of the robustness studies. Conclusions are in section 4.

\section{The model}

The IIASA model, which is more fully described in MacKellar and Ermolieva (1999) and based on work originally presented by Blanchet and Kessler (1992), is a neoclassical two-factor multiregional economic-demographic model with a particular focus on social security. ${ }^{1}$ It incorporates exogenous population projections, saving, labor force participation, and tax rates. The wage rate and rate of return to capital are endogenously calculated as marginal products of labor and capital. The emphasis of the model is on tracking income and outlay of households by single-year age groups, as well as the intergenerational transfer of resources via bequests. Households accumulate assets during working years and then "dissave" in retirement, in addition to which, intergeneration transfers between the working and retired populations are mediated

\footnotetext{
${ }^{1}$ An earlier model version which lacked full demographic dynamics is described by MacKellar and Reisen (1998a and 1998b).
} 
through the PAYG public pension system. While the model is suited to a wide range of applications dealing with long-run economic growth, it is especially designed to simulate the effects of differing demographic futures and different mixes between accumulation-based and transfer-based pension systems.

A special feature of the model is that it is multiregional, with allowance made for capital flows between regions or countries characterized by different demographic conditions and pension arrangements. For purposes of the robustness analysis presented here, however, we have collapsed the model to its single-region form, and no attempt will be made to describe its multiregional structure.

The core of the model is a Cobb-Douglas production function. Gross domestic product $(G D P)$ is

$G D P(t)=\alpha(t)(1+g(t))^{t} K(t)^{\beta(t)} L(t)^{(1-\beta(t))}$

where $g$ is the rate of total factor productivity growth. We assume, based on factor income shares observed in developed countries, that $\beta(t)=0.33$. Rates of return to factors are

$$
\begin{aligned}
& R(t)=\beta(t)\left[\frac{G D P(t)}{K(t)}\right] \\
& \overline{\text { Wage }}(t)=[1-\beta(t)]\left[\frac{G D P(t)}{L(t)}\right]
\end{aligned}
$$

$R$ is the gross profit rate, including depreciation and indirect taxes net of subsidies; and $\overline{\text { Wage }}$ is average (over age groups) employee compensation, including social insurance contributions (workers' and employers' contributions to public and private pension schemes). Age-specific wages are calculated based on years of experience in the labor force.

Age-specific saving and labor force participation rates are exogenous; thus, the IIASA model in its present form is essentially an accounting model. For given population size, age structure has three effects on per capita income: first, through the labor force as it affects the number of workers relative to non-workers; second, through capital formation, as it affects the number of savers relative to dissavers; third, and also through capital formation, as it affects the wage rate and rate of return to capital, which in turn determine the income streams which give rise to saving. In concentrating on relatively detailed age-structure effects, work with the IIASA model complements other analyses (e.g., Börsch-Supan, 1996, Cutler et al., 1990) in which the impact of population aging is mediated through the life cycle hypothesis of household consumption. Closely related to these are macroeconomic model-based analyses (e.g., Masson and Tryon, 1990), in which the impact of aging is mediated through the major macroeconomic functions, particularly the aggregate consumption/saving function. Given theoretical ambiguities, a simple accounting model with ample demographic detail provides a useful benchmark for work with more economically sophisticated, but demographically sparse, models. 
The model tracks receipts and disbursements, and thus net savings, by institutional sector (persons by single-year age group, firms, government). Following the convention of the OECD national income accounts, net savings in each sector of the economy are defined as gross receipts minus depreciation minus current expenditure. The sum of net savings across sectors is equal to net saving for the economy as a whole (national disposable income minus private consumption minus government consumption), which is in turn equal to net capital formation, i.e. change in the capital stock. Savings of firms and government are imputed to households based on the population age distribution. Capital consists of residential capital (KRes), capital operated by private unincorporated enterprises (KPvtUnincorpEnt), and capital operated by firms (i.e., corporate enterprises). Claims on capital operated by firms are held on behalf of households by two financial intermediaries: the private pension system (PvtPenSys) and other financial institutions (OthFinIns). All claims consist of equity. Imputed rents (in the case of residential capital) and the profits of capital operated by private unincorporated enterprises accrue directly to households. Firms earn profits, pay taxes and distribute dividends to holders of claims. Profits are taxed only once, when (and in the multiregional case, where) they are earned.

Two annexes are appended to give a flavor of the model. In Annex 1, we present a summary description of the life-cycle dynamics of capital accumulation and decumulation. During working life, households accumulate savings through contributions to the private pension system; after retirement, they receive pension benefits which represent the drawing-down of this capital. Savings not captured by the pension system are distributed between the three remaining asset classes by means of share coefficients which sum to unity. Any assets remaining upon death are distributed to the surviving population as bequests. Persons receiving bequests in the form of inheritance are assumed to these convert the inherited assets to cash, some of which is allocated to consumption and the remainder of which is allocated among the three nonpension forms of wealth.

The second major component of social security is the public pension system, which, as described in Annex 2, is assumed to be a PAYG system. Upon retirement, a public pension entitlement is calculated on the basis of past years of labor force participation and average wage earnings. During retirement, this entitlement is indexed to growth in average real wages using an assumed indexation factor. Thus, social security benefits for members of a given single-year age cohort are a weighted average over number of retirees, number of years of labor force participation (and average earnings) prior to retirement, and number of years elapsed since retirement. In the model runs presented in this paper, the social security payroll tax rate (levied against wage income and income from private unincorporated enterprises) is fixed, so demographic pressures on the pension system are reflected in a widening system deficit. This, in turn, reduces national savings and, in the single closed-region case examined here, capital formation. Alternative model closures can incorporate rising payroll tax rates and/or declining levels of retirement benefit. 


\section{Robustness studies: numerical experiments}

\subsection{Some robustness issues}

When evaluating quantitative modeling and analysis, robustness is often one of the main criteria to consider. This is certainly true for statistical analysis, econometric modeling, forecasting, etc., but it is also highly relevant when verifying the characteristics of a simulation model such as the one discussed in the present paper. A methodology is robust if its properties are not significantly changed when the assumptions it is based on are marginally different. Thus, robustness is generally a positive characteristic. It does not refer to situations where underlying assumptions are drastically changed, a case when the analysis is expected to, and also generally should, provide a set of new characteristics.

In econometric modeling, the statistical analysis is generally based on some of the following assumptions:

- residual distributions are symmetric, and not too heavy tailed (e.g. normal);

- residuals are homoskedastic, and without autocorrelation;

- processes to be modeled are stationary;

- functional forms specified are linear, or possible to be linearized;

- structures are not seriously misspecified;

- structures are stable over time or in space;

- no measurement errors, etc.

Some statistical procedures tend to be very sensitive towards deviations from such assumptions, other are less sensitive, i.e. have higher robustness. When considering robustness properties of the present paper's simulation of processes related to social security, it is obviously of interest to verify the effects of slightly different model specifications. In particular, the assumptions concerning structural parameters should be taken into account. For a comprehensive discussion of this topic in econometrics, see Hackl and Westlund (1991).

First, the robustness towards randomizing initial parameters assumptions should be verified. Second, the assumptions of parameter time invariance should be considered, i.e. robustness toward new parametric regimes, or shocks on the parameter structure should be analyzed. In the next section a simple robustness study with this particular focus is introduced.

\subsection{Generation of unc ertainties}

The purpose of the numerical experiments is to randomize the parameters of the system and analyze the responses of the three selected variables to the simulated uncertainties. The parameters stochastically perturbed were the coefficient of the CobbDouglas production function $\beta(t)$; age specific labor force participation rates, 
LabForcePartRate(age,t); and consumption rates AvgPropCons(age,t). ${ }^{2}$ Normal distributions and rather small standard deviations used in these studies for the simulation of the uncertainties represent stochastic disturbances in a moderate way, in addition to which, the normal distribution of the parameters often enables us to get an analytical representation of the distribution of the explored variable.

We chose to study three simple types of uncertainties, which in a general form are described as follows:

\section{1) Randomization of initial assumptions of a parameter at time $t=1$}

The parameter was drawn from a normal distribution with a mean equal to the base scenario parameter value and standard deviation equal to $10 \%$ of the mean. For each $t>1$ the value of the parameter was set equal to the value at $t=1$ (note that all three shocked parameters are time-invariant in the baseline scenario). For example, if the studied parameter is $\beta(t)$, then $\beta(t) \sim N(0.33,0.033)$.

\section{2) Randomization at $t=1$ with an independent "shock" at time $t=t_{1}$}

The time of the "shock", $t_{1}$, in general may be random itself. In this paper we assume $t_{1}=30$, which is approximately one third of the way through the 100 time intervals observed (the year 2025). At $t=1$ the parameter was drawn from a normal distribution with mean equal to the base scenario value and standard deviation equal to $10 \%$ of the mean (as in the previous paragraph). For $t, 1<t<30$, the value of the parameter was kept equal to that obtained at $t=1$. At $t=30$ the regime of the parameter changed to a normally distributed with mean equal to the base scenario value and standard deviation equal to $5 \%$ of the mean. Assume the parameter is $\beta(t)$, then $\beta(t) \sim N(0.33,0.033)$ for $t=1, \ldots, 29$, and $\beta(t) \sim N(0.33,0.0165)$ for $t \geq 30$. Since the shock at $\mathrm{t}=30$ is drawn from a distribution with a smaller variance than the shock at $\mathrm{t}=1$, all else being equal, we expect a narrower uncertainty band.

\section{3) Randomization at $t=1$ with path dependent "shock" at $t=t_{1}$}

The third case of uncertainty took advantage of an autoregressive function to incorporate the "history" on previously obtained parameter values and to bridge the value of parameter at $t=1$ with the value at $t=t_{1}$. At time $t=1$ the parameter was chosen similar to 1 ) above. At $t=30$ the parameter switched to a normally distributed with mean equal to the parameter value at $t=1$ multiplied by the uniformly distributed on the interval $[0.85,0.9]$ random variable, and standard deviation equal to $5 \%$ of the mean. For example, if the parameter is $\beta(t)$, then $\beta(t) \sim N(0.33,0.033)$ for $t=1, \ldots, 29$. For $t \geq 30, \beta(t) \sim N(\hat{\beta}(29) k, 0.05 \hat{\beta} k)$, where $\hat{\beta}(t)$ is a realization of a parameter at $t$, and $k$ is a uniformly distributed on the interval $[0.85,0.9]$ variable.

Note that just because shocks are comparable in terms of the standard deviation of the normal distribution from which they are drawn, this does not mean that they are comparable in economic policy terms. For example, a shock equal to one standard

\footnotetext{
${ }^{2}$ In the case of LabForcePartRate(age,t) and AvgPropCons(age,t), the shock was administered uniformly (in proportional terms) over the entire age spectrum. In the latter case, identical shocks were applied to average propensities to consume out of each income stream. Finally, the share of inherited assets converted to consumption was subjected to the same proportional shock as AvgPropCons(age,t).
} 
deviation of the $\beta(t)$ parameter might shift $\beta(t)$ from 0.33 to 0.36 . Most commentators would judge this a significant, but modest change. Say, on the other hand, that the household saving rate (averaged over age groups) is 10 percent, implying an average propensity to consume of 90 percent. A one-standard deviation decrease in all agespecific consumption rates would reduce the consumption rate to 81 percent, causing the average household saving rate to nearly double, to 19 percent. For this reason, we are careful in the following discussion not to compare sensitivities across simulations.

The results of simulations are presented in graphical form providing some important percentiles of the sample. Different cases are identified by $C(i, j, k)$ where $i=1,2,3$ indexes the perturbed parameter; $j=1,2,3$ indexes the type of the uncertainty and $k=1,2,3$ indexes the variable whose behavior we are exploring. For example, $C(1,1,1)$ stands for the case with parameter $\beta(t)$, first type of uncertainty, and assets of private pension funds. experiments.

In the interests of economy, we present only the most illustrative results of the

\subsection{Numerical results}

The baseline scenario from 1995-2000 was produced using generic assumptions suitable to an industrial economy. Since all results -- economic growth path, saving rates, rates of return to capital and labor, the capital-output ratio, the government balance (including balance of the PAYG pension system), and relative income of the non-working elderly -- were reasonable, no attempt was made to fine-tune results. The robustness results reported here are quite unlikely to be sensitive to the baseline scenario employed.

\subsubsection{KPutPenSys(t)/GDP(t), uncertainties in parameter $\beta(t)$, cases $C(1,, 1)$.}

The variable KPvtPenSys $(t)$ is normalized by $G D P(t)$. The impact of increasing $\beta(t)$ is to increase $G D P(t)$ and raise the rate of return to capital. ${ }^{3}$ Since $G D P(t)$ is a fastmoving flow variable and $K P v t P e n S y s(t)$ is a slow-moving stock variable, the impact is thus to reduce private pension system assets relative to GDP. In the long run, $K P v t P e n S y s / G D P$ is closely related to the capital-output ratio $K / G D P$, which in a growth model based on the Cobb-Douglas production function converges to an equilibrium value of

$$
\frac{K}{G D P}=\left(\frac{s a}{r}\right)^{\frac{1}{1-\beta}}
$$

\footnotetext{
${ }^{3}$ Say $\beta(t)$ increases from 0.33 to 0.36 ; then $1-\beta(t)$ declines from 0.67 to 0.64 . The former is a 10 percent increase and, for given capital stock and ignoring higher-order effects, will increase GDP by 3.3 percent. The latter is a 4.5 percent decrease and, again for given labor force and ignoring feedback effects, will decrease GDP by $0.67 \times 4.5=3.0$ percent. The net effect of the increase in $\beta(t)$ is thus to increase GDP by approximately 0.3 percent.
} 
where $\mathrm{s}$ is the saving rate (savings as a proportion of GDP), $\mathrm{r}$ is the rate of economic growth, and $\mathrm{a}$ is the constant term in the Cobb-Douglas function. When $B$ is subjected to a sustained shock, KPvtPenSys/GDP, like the capital-output ratio, will converge to a new long-run equilibrium value.

It is worth noting that the slopes of the curves shown in Figure 1 represent net inflows to the pension system; therefore, we see that the baseline and shocked scenarios reflect the declining rate of net financial inflow, which is expected as the population ages. Nothing in these scenarios gives credence, however, to what the popular economic press termed "asset meltdown," that is, financial outflows amounting to a catastrophic financial hemorrhage.

Figure 1 illustrates case $C(1,1,1)$. Uncertainty band trajectories start off from different positions, reflecting the initial-year shock to $\beta(t)$, and develop in parallel, reflecting the fact that the shock is a sustained one. After 50 time periods (year 2045) the trajectories stabilize. The 5-th and 95-th percentiles are symmetrical with respect to the mean trajectory, though the mean and the median (50\%) do not really coincide, which might indicate slightly skewed distribution of the ratio. The uncertainty bandwidth, i.e. the 95 percent confidence interval, is roughly 20 percentage points of GDP.

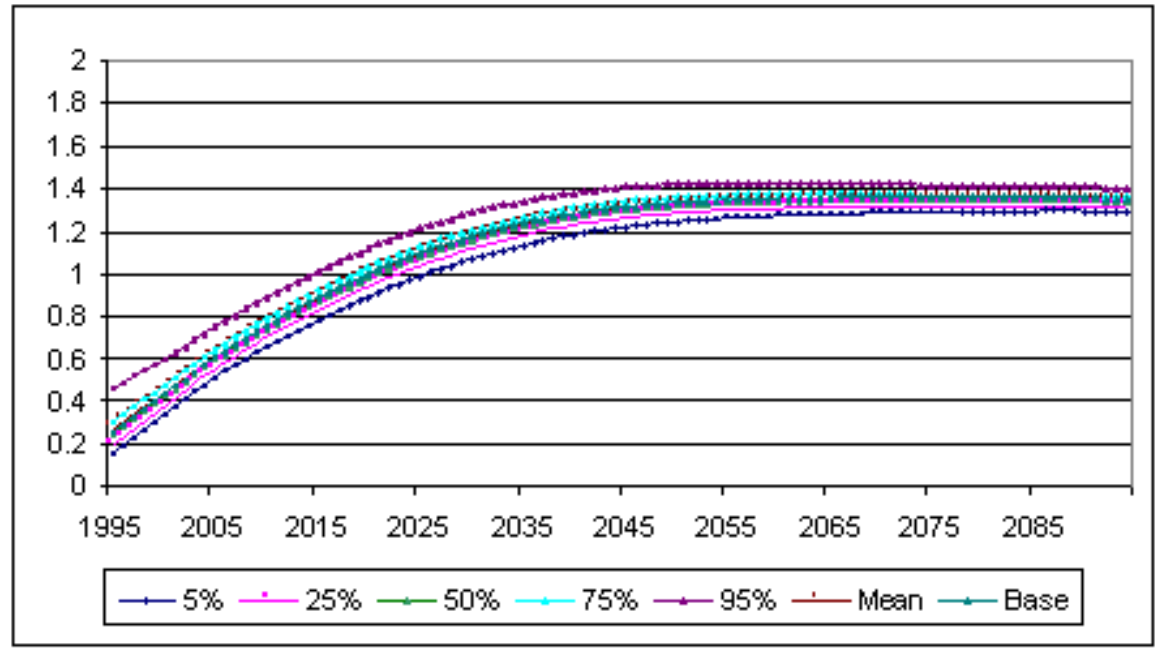

Figure 1. Percentiles, mean and base trajectories of the ratio $\operatorname{KPvtPenSys}(t) / G D P(t)$, case $C(1,1,1)$.

In Figure 2 we present the case $C(1,2,1)$. Until 2025 (the first 29 years) the trajectories develop as in $C(1,1,1)$. At $t=30$, the time of the second shock, they shift sharply. Reconvergence requires about 50 years. The more rapid reconvergence following the second shock, compared to the first, reflects the fact that by 2025, the capital-output ratio, and by extension the closely-related variable $K P v t P e n S y s(t) / G D P(t)$, is closer to its long-run equilibrium value. The main conclusion 
to be drawn from Figure 2 is that the system is stable and, at least in the long run, robust to shocks in the parameters of the production function.

In case of the third type of uncertainty in $\beta(t)$ (see Figure $3, C(1,3,1)$ ) the shock in 2025 is administered to the already-shocked (in 1995) value of $\beta(t)$. The shock consists of multiplying $\beta$ (29) by a random variable uniformly distributed on the interval $[0.8,0.95]$. GDP immediately shifts down (see Footnote 3 ), but the capital-output ratio shifts up, and along with it KPvtPenSys/GDP. Reconvergence occurs as in the previous case.

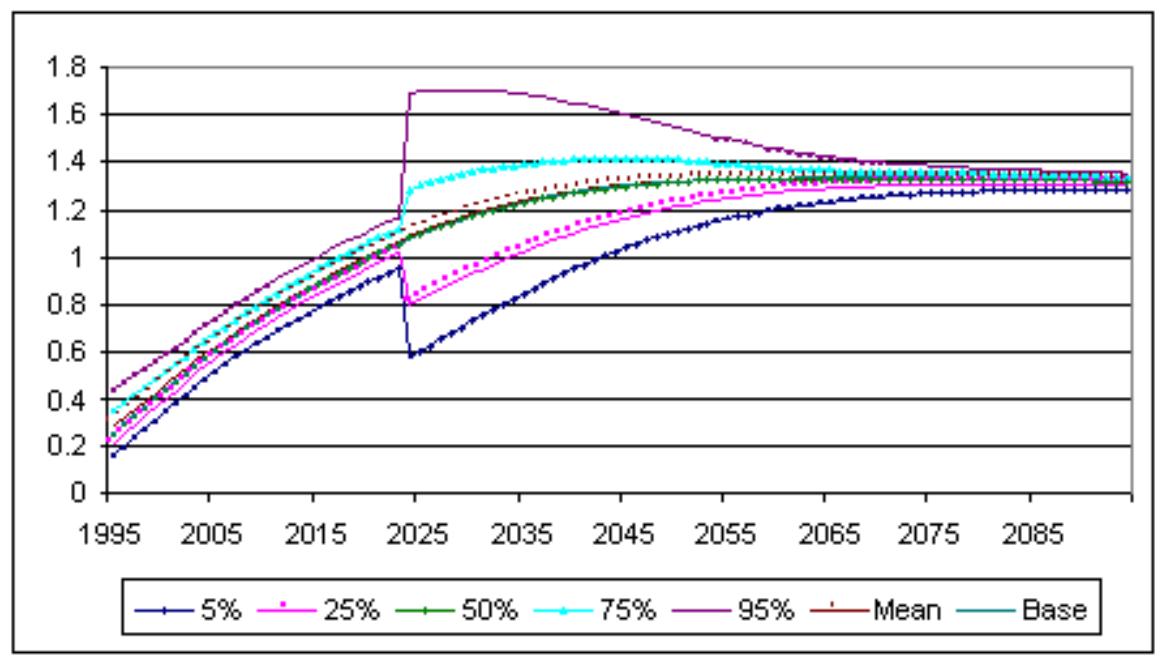

Figure 2. Percentiles, mean and base trajectories of the ratio KPvtPenSys/GDP, case $C(1,2,1)$.

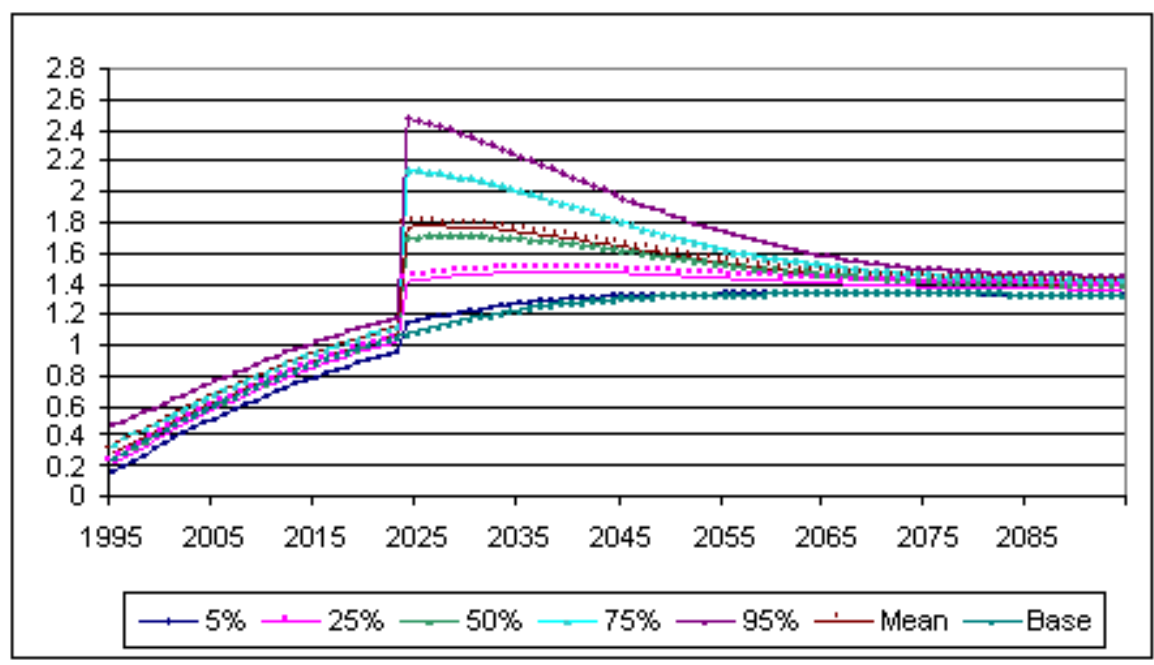

Figure 3. Percentiles, mean and base trajectories of the ratio KPvtPenSys/GDPP, case $C(1,3,1)$. 


\subsubsection{KPutPenSys(t)/GDP(t), uncertainties in parameter LabForcePartRate, cases $C(2, ; 1)$.}

It is often argued that pension systems of all types are extremely sensitive to labor force participation rates, especially among older persons. This argument is based the view that a decline in the labor force participation rate of the elderly has a double effect, increasing the number of persons drawing funds out of the pension system while simultaneously reducing the number of persons paying in.

This may be true for large absolute shifts in labor force participation rates, corresponding to structural changes in the labor market. For example, the labor force participation rate of elderly men in some OECD countries has fallen by some 20 percentage points in the post-War period. However, Figure 4 indicates that, notwithstanding feedback effects, moderate proportional shifts in labor force participation rates have similarly modest impacts on assets of the pension private system (the impact on the PAYG pension system, discussed below, is greater). In the baseline scenario, the average (over age groups) labor force participation rate for persons aged 20-65 was approximately 80 percent and for persons aged over 65 was approximately 10 percent. The first vector of age-specific stochastic shocks, administered in 1995, reflects standard deviations equal to 10 percent of baseline age-specific labor force participation rates. The second vector of shocks, administered in 2030, reflects standard deviations equal to 5 percent of the baseline labor force participation rate. While it appears from Figure 4 that the model is more sensitive to the second, proportionally smaller, set of shocks, this is a scale effect which arises from the fact that the variable being analyzed roughly quadruples over the time interval intervening between the first and second shocks. In fact, the "fanning out" of KPvtPenSys $(t) / G D P(t)$ as a result of the shock is about the same, proportionally speaking, in 1995 as it is in 2030. As in the case of the shocks considered in the previous section, reconvergence is more rapid when $K P v t P e n S y s / G D P$ is close to its equilibrium value.

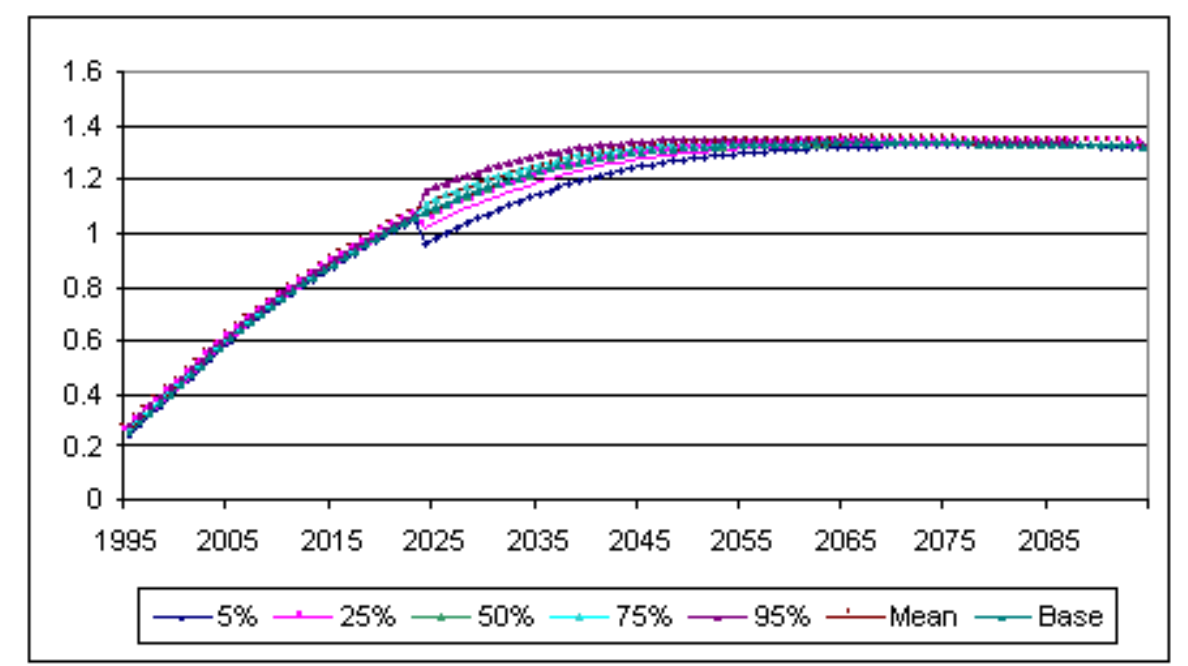

Figure 4. Percentiles, mean and base trajectories of the ratio KPvtPenSys/GDP, case $C(2,2,1)$. 


\subsubsection{KPvtPenSys(t)/GDP(t), uncertainties in parameter AvgPropCons,} cases $C(3, \cdot, 2)$

Case $C(3,2,1)$, illustrated in Figure 5, corresponds to the second type of uncertainty in AvgPropCons. A sustained downward (upward) shock to AvgPropCons leads to a permanent increase (decrease) in the ratio KPvtPenSys/GDP. To see why, consider a simple example in which the saving rate is 10 percent and a single one-year shock raises it to 11 percent. If the ratio of capital to GDP is 3, then ceteris paribus, the capital stock will be increased by 0.33 percent. Assuming that the extra savings are distributed as before between assets held by pension funds and other institutions, KPvtPenSys will also increase by 0.33 percent. Assuming $\beta(t)=0.33$, GDP will increase by $(0.33 \times 0.33)=0.109$ percent, meaning that the ratio KPvtPenSys/GDP will rise by 3 percent. The impact on the long-run equilibrium value of KPvtPenSys/GDP can be appreciated at least qualitatively by examining the algebraic expression given in Section 3.3.1 for the equilibrium value of the capital-output ratio.

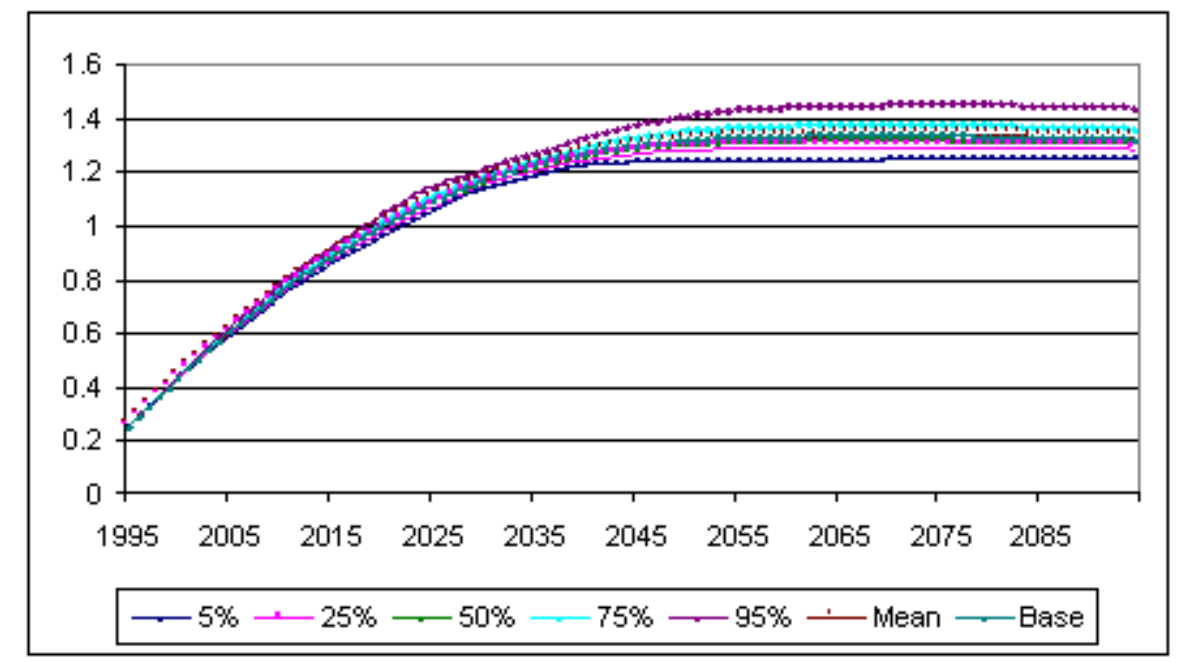

Figure 5. Percentiles, mean and base trajectories of the ratio KPvtPenSys/GDP, case $C(3,2,1)$.

\subsubsection{Ratio of income per non-working member of the population over 65 to inc ome per worker, uncertainties in parameter $\beta(t)$, cases}

\section{$C(1, \cdot, 2)$.}

In the baseline scenario, the initial value of this relative income ratio is approximately 0.7 . In case $C(1,2,2)$, illustrated in Figure 6 , the post-shock trajectories start from an uncertainty band of approximately $0.55-0.85$ and there is rapid reconvergence. The same process is repeated after the second shock. Underlying the evident robustness of the income ratio is the following story. When $\beta(t)$ increases, the wage bill declines while non-working elderly persons' rentier income increases. Transfer payments mediated through the social security system remain the same, because these are based on the wage history of current retirees. Thus, income per non- 
working elderly person increases relative to income per worker. In the longer run, social security entitlements decline to match the lower wage history of new retirees, in addition to which, new retirees will have saved less as a result of lower wages earned while working. The greater the role of the PAYG pension system in the overall social security regime, and the shorter the past earnings reference period with respect to which initial pension entitlement is calculated, the more rapid the reconvergence.

\subsubsection{Ratio of income per non-working elderly person to income per worker, unc ertainties in parameter LabForcePartRate, cases $C(2, \cdot, 2)$.}

This series of experiments, illustrated in Figure 7, is represented by the case $C(2,2,2)$. When LabForcePartRate increases, the immediate result is to drive down the wage rate, thus reducing income per worker, while increasing the real rate of return to capital. Social security payments per non-working elderly person are not affected because of the fixed benefit of current retirees; if anything, the income of the nonworking elderly increases somewhat because of higher rentier income. The net result of the changes is to increase the relative income of the non-working elderly. In the long run, income per non-working elderly person declines to reflect the fact that fewer of the elderly worked while young; workers are saving less because of the lower wage rate, but are earning a higher rate of return on their savings. On net, as seen in Figure 7, the displacement in the income ratio cause by the shock to LabForcePartRate is a permanent one. The narrower band of uncertainty following the second shock reflects the fact that the disturbance is drawn from a distribution with smaller variance.

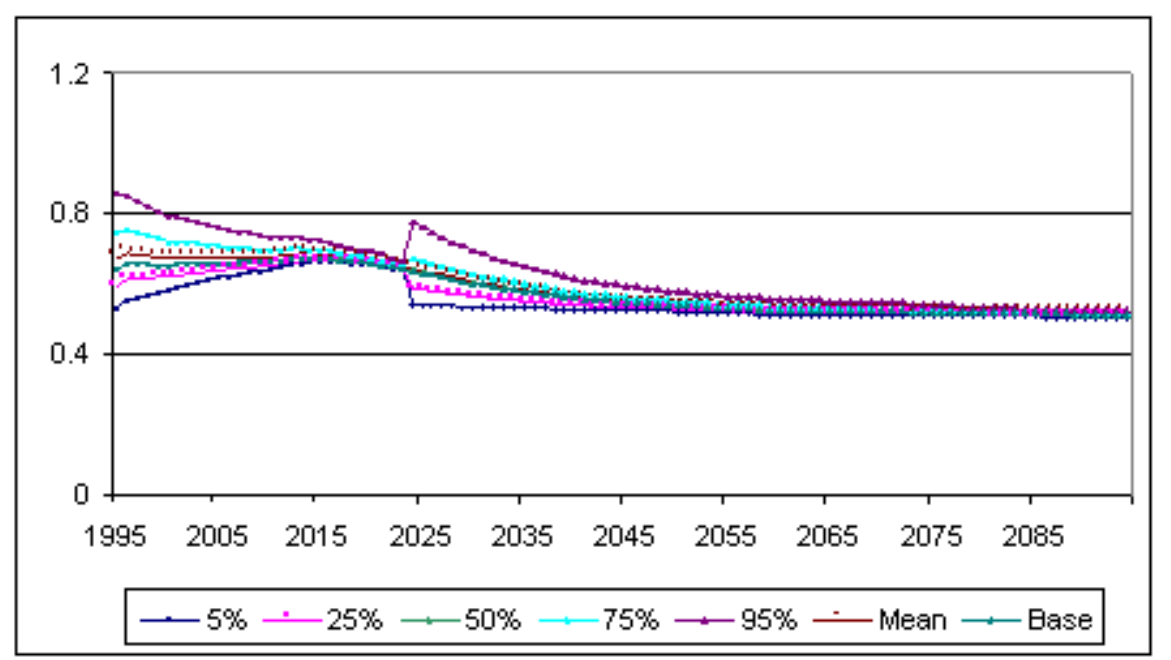

Figure 6. Percentiles, mean and base trajectories of the ratio of income per nonworking elderly person to income per worker, case $C(1,2,2)$. 


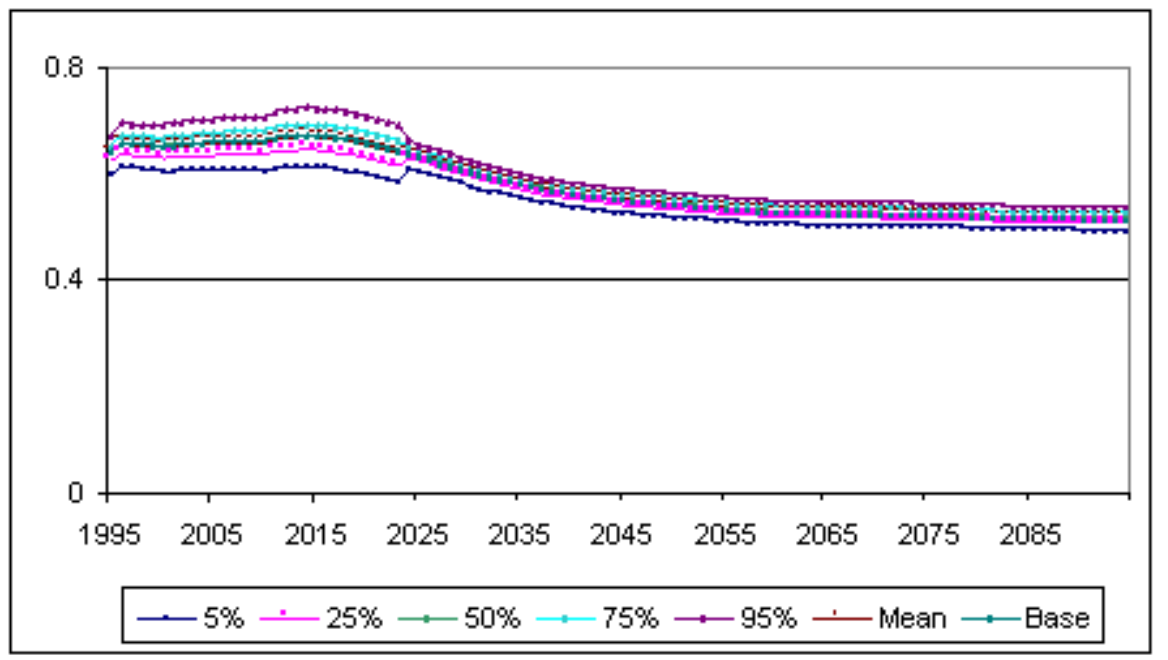

Figure 7. Percentiles, mean and base trajectories of the ratio of income per nonworking elderly person to income per worker, case $C(2,2,2)$.

\subsubsection{Ratio of income per non-working elderly person to income per worker, uncertainties in parameter AvgPropCons, cases $C(3, ; 2)$.}

When AvgPropCons is shocked downward, the resulting increase in the saving rate accelerates growth in the capital stock and GDP and drives down the rate of return to capital while increasing the wage rate (see Figure 8). Workers' income rises, but so does the non-working elderly's income as a result of enhanced transfer payments through the social security system, higher lifetime savings, and higher rate of return to saving. While the net result is an increase in the relative income of the non-working elderly, this is modest and entirely long-term in nature.

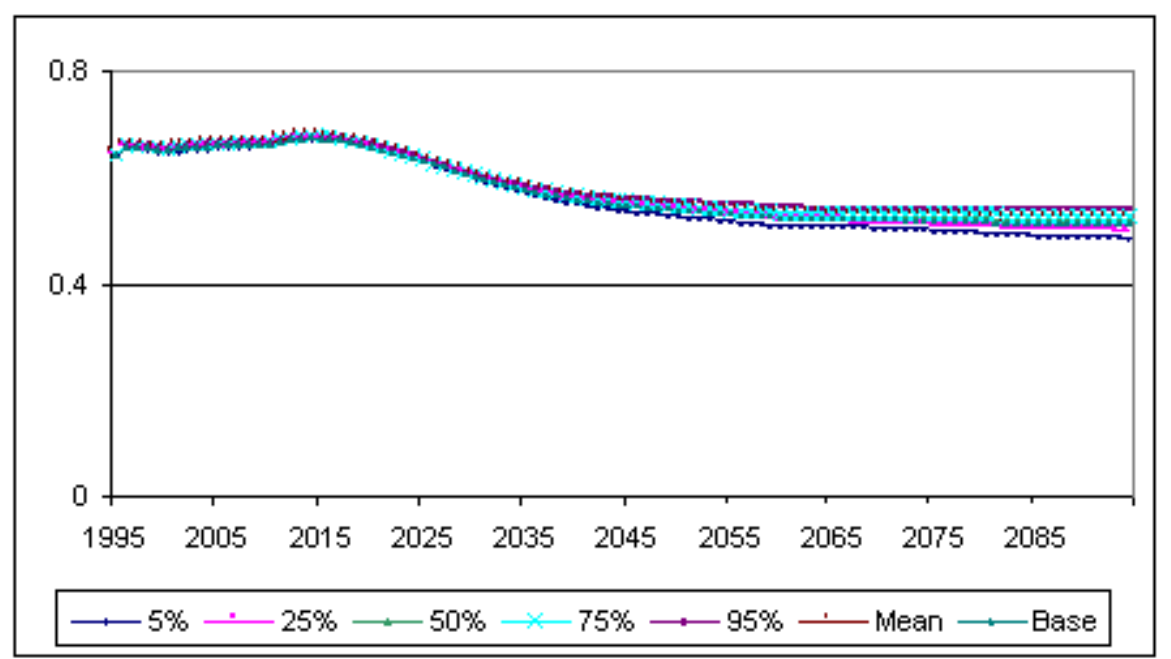

Figure 8. Percentiles, mean and base trajectories of the ratio of income per nonworking elderly person to income per worker, case $C(3,2,2)$. 


\subsubsection{Balance of the PAYG pension system / GDP, uncertainties in parameter $\beta(t)$, cases $C(1, ; 3)$}

The deficit of the PAYG pension system is normalized by GDP. In order to be consistent for each of three randomized parameters we have chosen to illustrate only the second type of uncertainty, that is, $C(\cdot, 2,3)$. However, the results (see Figure 9) also allow us to get a feeling for what would happen in the first and the third case of uncertainty. In the baseline scenario, the impact of population aging is to reduce an initial surplus on the order of 5 percent of GDP to a long-run deficit on the order of 2 percent of GDP. The most rapid deterioration corresponds to the retirement of the baby boom generation, after which the deficit stabilizes relative to GDP. The deficit is quite robust to shocks administered to $\beta(t){ }^{4}$

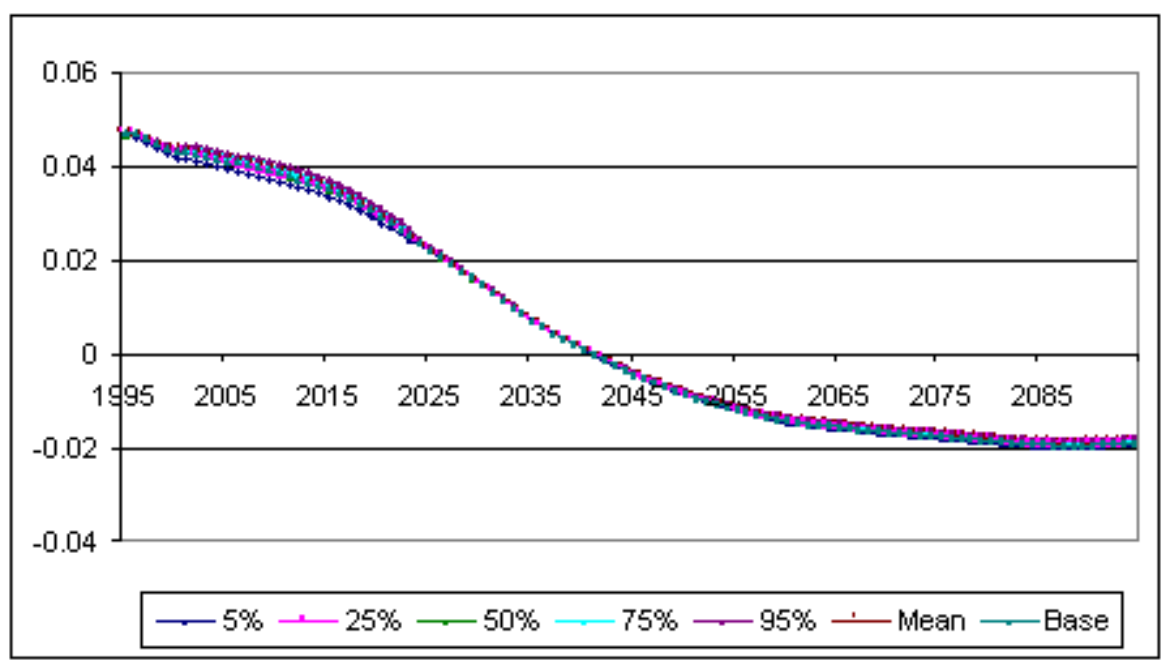

Figure 9. Percentiles, mean and base trajectories of the balance of the PAYG pension system/GDP, case $C(1,2,3)$.

\subsubsection{Balance of the PAYG pension system/GDP, uncertainties in parameter LabForcePartRate, cases $C(2, ; 3)$}

On the assumption that system obligations per retiree and the payroll tax rate are both fixed, lower labor force participation, especially among the elderly, increases the

\footnotetext{
${ }^{4}$ In order to understand why, consider the example given above in Footnote 3, from which we concluded that an increase in $\beta(t)$ from 0.33 to 0.36 , accompanied by a corresponding decrease in $1-\beta(t)$, would increase GDP by approximately 0.3 percent. Say pre-shock GDP was 100 and post-shock GDP was 100.3. The wage bill would decline from $0.67 \times 100=67$ to $0.64 \times 100.3=64.192$, a decline of 4.5 percent. Say that the payroll tax rate was 10 percent, making for social security system revenues of 6.7 , and expenditures were 1.7, making for a ratio of the social security system balance to GDP of 5 percent. Given social security system obligations which are fixed in the near term, post-shock system expenditures would still be 1.7. Given a fixed payroll tax rate, post-shock revenues are 0.1 x $64.192=6.1492$. The new system balance is $6.1492-1.7=4.4492$ and the new ratio of system balance to GDP is 4.4492 / $100.3=4.436$ percent. This is not an exceptionally large shift.
} 
PAYG social security system deficit. The increase in the deficit relative to GDP is accentuated by the fact that GDP is reduced by lower labor force. As can be seen in Figure 10, the 1995 stochastic shock based on a distribution with standard deviation equal to 10 percent of the baseline mean labor force participation rate produces an uncertainty band of a bit less than 2 percent of GDP. Not surprisingly, the 2025 shock based on a standard deviation half this size produces an uncertainty band of roughly 1 percent of GDP. There is no tendency to reconvergence. First, the sustained shift in labor force participation causes a sustained shift in the ratio of system contributors to system beneficiaries. Second, system obligations are driven in opposite directions by two countervailing forces. In the long run, lower labor force participation raises the ratio of elderly who never worked to elderly who worked; all else being equal, this reduces system obligations. Because of lower labor supply, however, those who worked earned higher wages and thus have a higher pension entitlement; all else being equal, this increases system obligations.

\subsubsection{Balance of the PAYG pension system/GDP, uncertainties in parameter AvgPropCons, cases $C(3 ;, 3)$}

The case $C(3,2,3)$ is presented (see Figure 11) only to illustrate that household saving rates have virtually no impact on the PAYG pension system deficit. Over the long run, higher savings mean a larger capital stock and higher GDP; on the other hand, the associated higher capital-output ratio is translated into higher wages and hence higher pension entitlements. System revenues are higher as a result of the higher wage bill, but system obligations are higher as well.

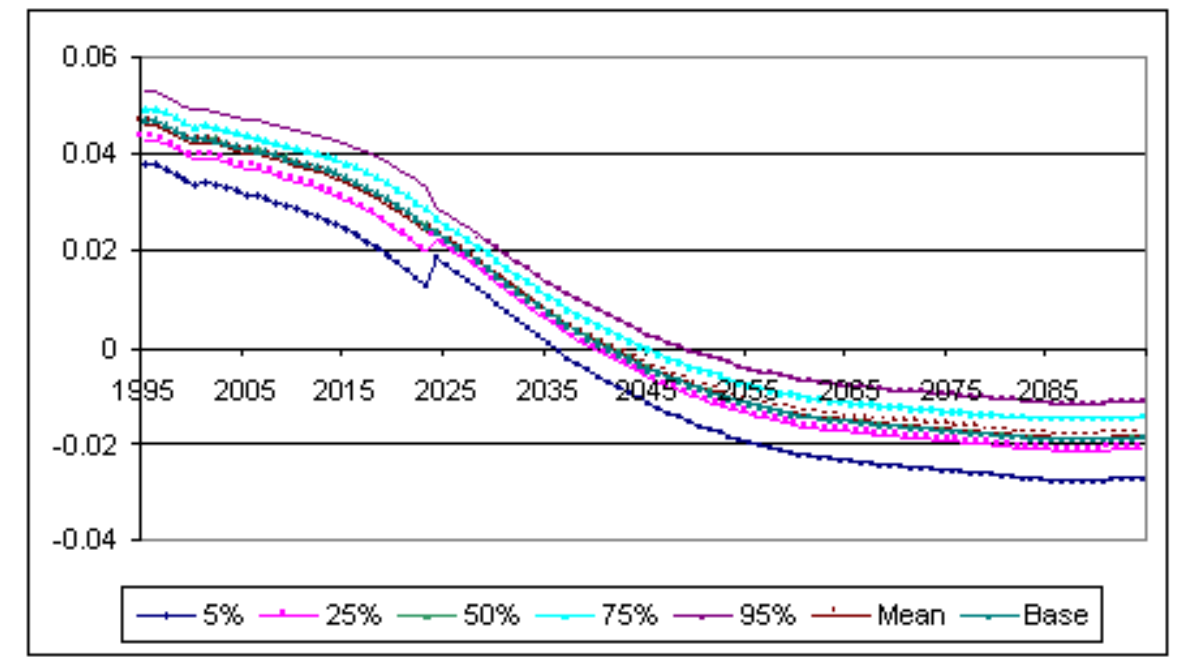

Figure 10. Percentiles, mean and base trajectories of the balance of the PAYG pension system/GDP, case $C(2,2,3)$. 


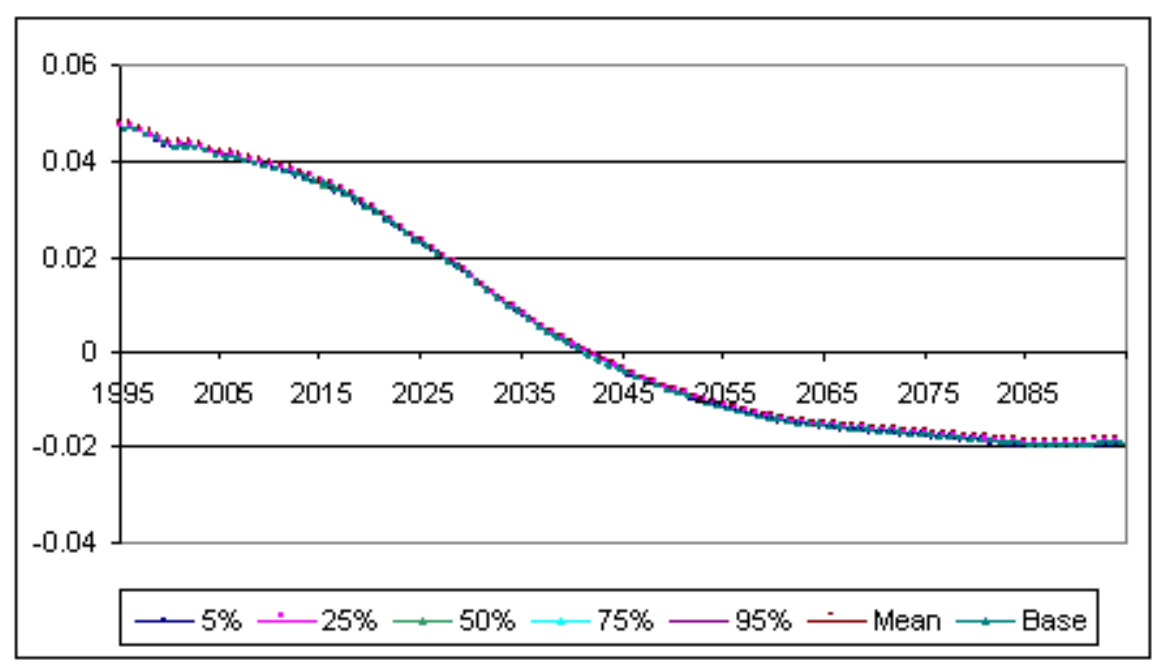

Figure 11. Percentiles, mean and base trajectories of the balance of PAYG pension system/GDP, case $C(3,2,3)$.

\section{Conclusions}

The IIASA model described in Section 2 is designed to study the likely evolution of a handful of major macroeconomic variables as a function of the age distribution of the population and the nature of pension arrangements. In this paper, we studied the impact of uncertainty in model parameters on three variables of special interest in the social security debate: assets of the private pension system, the relative income of the non-working elderly, and the balance of the PAYG pension system. The results indicate that confidence bounds can and should be estimated and presented when scenarios are constructed using such a model.

The most important insights gained have to do with the credibility of the model and thus of studies based upon it. First, the model is sensible: in each case examined, a reasonable story can be told to explain the qualitative nature of the impact of the shock. A non-stochastic simulation exercise could also have established the simulation properties of the model. However, our stochastic approach has allowed us to establish a second, equally important result: the model is stable, meaning that shocks drawn from a reasonable probability distribution give rise to a similarly reasonable distribution of impacts. 


\section{References}

Blanchet, D. and D. Kessler (1992), Pension Systems in Transition Economies: Perspectives and Choices Ahead, in P. Pestieau (ed.), Public Finance in a World of Transition, Supplement to Public Finances/Finances Publiques, Vol. 47.

Börsch-Supan, A. (1996), The Impact of Population Aging on Savings, Investment and Growth in the OECD Area, in OECD (ed.), Future Global Capital Shortages: Real Threat or Pure Fiction?, OECD, Paris.

Cutler, D., J. Poterba, L. Sheiner and L. Summers (1990), An Aging Society: Opportunity or Challenge?, Brookings Papers on Economic Activity, 1990:1.

Hackl, P. and A.H. Westlund (1991), Economic Structural Change Analysis and Forecasting, Springer, Berlin.

James, E. (1998), New models for old-age security: experiments, evidence, and unanswered questions, World Bank Research Observer 13(2):271-301.

MacKellar, L. and T. Ermolieva (1999), The IIASA Multiregional EconomicDemographic Model: Algebraic Structure, IIASA Interim Report, forthcoming.

MacKellar, L. and H. Reisen (1998a), A simulated model of global pension investment, OECD Development Centre, Technical Paper No. 137.

MacKellar, L. and H. Reisen (1998b), International diversification of pension assets is no panacea for population aging, IIASA Interim Report, IR-98-34/June.

Masson, P. and R. Tryon (1990), Macroeconomic effects of projected population aging in industrial countries. IMF Staff Papers 37(3): 453-85.

OECD (1998), Maintaining prosperity in an ageing society, OECD, Paris.

Roseveare, D., W. Leibfritz, D. Fore and E. Wurzel (1996), Ageing Populations, Pension Systems and Government Budgets: Simulations for 20 OECD Countries, Economics Department Working papers No. 168,OECD, Paris.

Schieber, S. and J. Shoven (1994), The Consequences of Population Aging on Private Pension Fund Saving and Asset Markets, NBER Working Paper, No. 4665.

World Bank (1994), Averting the old age crisis, World Bank, Washington, D.C. 


\section{Annex 1: The life-cycle dynamics of capital accumulation}

There are four different types of capital: residential capital (KRes), capital operated by private unincorporated enterprises (KPvtUnincorpEnt), capital operated by firms and held on households' behalf by the private pension system (KPvtPenSys), and capital operated by firms and held on households' behalf by other financial institutions (KOthFinIns). Corresponding to each of the four types of capital is an age-specific capital accumulation equation which tracks assets as the population ages. The major structural difference is between KPvtPensSys and the other three asset classes. Funds flow into PvtPenSys only through payroll deductions (including deductions from entrepreneurial income) on behalf of system participants. Dividends earned on assets held by the PvtPenSys remain within the system until the worker retires. By contrast, savings of all origins, not just captive retirement-related savings, flow into KOthFinIns, KRes, and KPvtUnincorpEnt. Dividends earned on assets held by OthFinIns may be allocated to consumption at any point during the life cycle, as may profits accruing to KPvtUnincorp Ent (implicit rents on KRes are assumed to be consumed in their entirety). If saved, dividends earned on assets held by OthFinIns may remain within OthFinIns, or be allocated to residential investment or investment in capital operated by PvtUnincorpEnt.

\section{Private Pension System (PvtPenSys)}

The private pension system is assumed to be a fully-funded defined contribution system. No distinction is made between workers' and employers' contributions and the contribution rates out of wages and entrepreneurial income are assumed to be identical. Contributions are

$$
\begin{aligned}
& \text { PvtPenSysContWageY }(\text { age }, t)=P v t P e n S y \text { ContRate }(\text { age }, t) \text { WageY }(\text { age }, t) \\
& \text { PvtPenSysContEntrY }(\text { age }, t)=\text { PvtPenSysContRate }(\text { age }, t) \text { EntrY }(\text { age }, t)
\end{aligned}
$$

The age-specific accumulation equation for the private pension wealth is

$$
K P v t P e n S y s(\text { age }, t)=K P v t P e n S y s(t-1, \text { age }-1)+\Delta K P v t P e n s S y s(\text { age }, t)
$$

where

$$
\begin{aligned}
& \Delta K \text { PvtPenSys }(\text { age }, t)=\text { ContPvtPenSys }(\text { age }, t) \\
& \quad+\text { DividPvtPenSys }(\text { age }, t) \\
& \quad-\text { PvtPenSysBen }(\text { age }, t)-\text { BeqKPvtPenSys }(\text { age }, t)
\end{aligned}
$$


In order, the components of change are:

- current contributions (zero for persons who have retired),

- receipt of dividends,

- dissaving via the conversion of retirees' accumulated assets into consumption, and finally,

- outflow of funds via death of claimants and ensuing pay-out of their accumulation.

Note that, for an individual cohort born in year $t=0$ whose last members die out in year $t=$ MaxAge, lifetime pension contributions plus lifetime earnings on pension assets plus lifetime pension benefits received equals bequest of pension wealth; i.e.,

$$
\begin{aligned}
& \sum_{t=0}^{\text {MaxAge MaxAge }} \sum_{\text {age }=0} \Delta K P v t P e n S y s(\text { age }, t)
\end{aligned}
$$

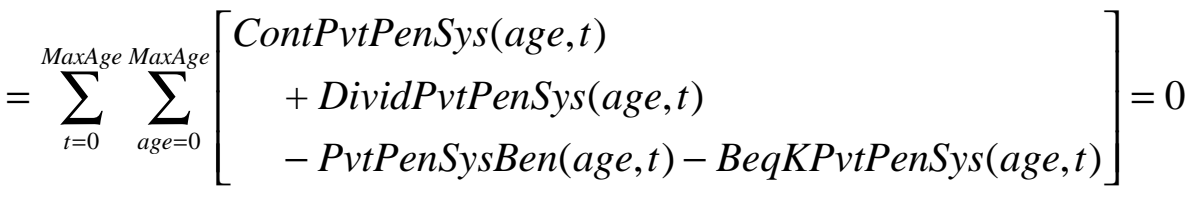

In accordance with the System of National Accounts, changes in pension fund equity are added to household savings from all other sources as an adjustment:

$$
\begin{aligned}
& \text { AdjNetSvngHH }(\text { age }, t)=\text { NetSvngHH }(\text { age }, t) \\
& \quad+\text { ContPvtPenSys }(\text { age }, t)+\text { DividErngsFirmsKPvtPenSys }(\text { age }, t) \\
& \quad-\text { PvtPenSysBen }(\text { age }, t)-\text { BeqKPvtPenSys }(\text { age }, t)
\end{aligned}
$$

where NetSvngHH covers all savings excluding change in pension fund equity.

\section{Other asset classes (KOthFinIns, KRes, KPutUnincomEnt)}

For $*=$ KRes, KPvtUnincorpEnt, and KOthFinIns, the age-specific accumulation equations are 


$$
\begin{aligned}
& \Delta K *(\text { age }, t)= \\
& K * \operatorname{Share}(t)[\operatorname{Net} \operatorname{SvngHH}(\text { age }, t)+\operatorname{NetSvngFirms}(\text { age }, t)+\operatorname{NetSvngGovt}(\text { age }, t)] \\
& \text { - DissvngK * (age,t) } \\
& +K * \text { Share }(t)\left[\begin{array}{l}
\text { DissvngK Re } s(\text { age }, t) \\
+ \text { DissvngKPvtUnincorpEnt }(\text { age }, t) \\
+ \text { DissvngKOthFinIns }(\text { age }, t)
\end{array}\right] \\
& \text { - BeqK } *(\text { age }, t) \\
& +\operatorname{Inh} K *(\text { age }, t)-\text { AssetSalesInhK } *(\text { age }, t) \\
& +K * \text { Share }(t)\left[\begin{array}{l}
\text { AssetSalesInhK } \operatorname{Re} s(\text { age }, t) \\
+ \text { AssetSalesInhKPvtUnincorpEnt }(\text { age }, t) \\
+ \text { AssetSalesInhKPvtPenSys }(\text { age }, t) \\
+ \text { AssetSalesInhKOthFinIns }(\text { age }, t)
\end{array}\right]
\end{aligned}
$$

The components of change are, in order:

- Unadjusted household net savings (i.e., not including savings captured by the private pension system) plus the imputed savings of firms and government. In imputing corporate and government savings to households by age group, shares drawn from the population age distribution are used. Another share variable, which sums to unity across the three forms of non-pension wealth, is used to apportion savings between $\bullet K R e s, \cdot K P v t$ UnincorpEnt, and $\bullet K O t h F i n I n s$. Note that allocation shares are not indexed by age. This simplification frees computer memory for tracking the results of numerous uncertainty simulations. Shares may be age-indexed in nonstochastic model application.

- The second line, of relevance only to retired households, subtracts dissaving in the form of sales of accumulated assets. The third line, also of relevance only for retired households, reflects the allocation of the proceeds of asset sales among the three forms of non-pension wealth. Consumption from the proceeds of asset sales is not subtracted because this consumption has already been factored into adjusted household net saving in the first line.

- The fourth line subtracts bequests, which represent a leakage of wealth out of the age group.

- The fifth line adds inheritance, an injection of wealth, and subtracts asset sales which occur in consequence of inheritance.

- The sixth and last line is analogous to the third line, but applies to households everywhere in the age spectrum and includes the disposition of inherited pension-, as well as non-pension, wealth.

\section{Accounting consistency check}

We now check that total net capital formation is equal to total net savings. First, adding across the three non-pension forms of wealth, 


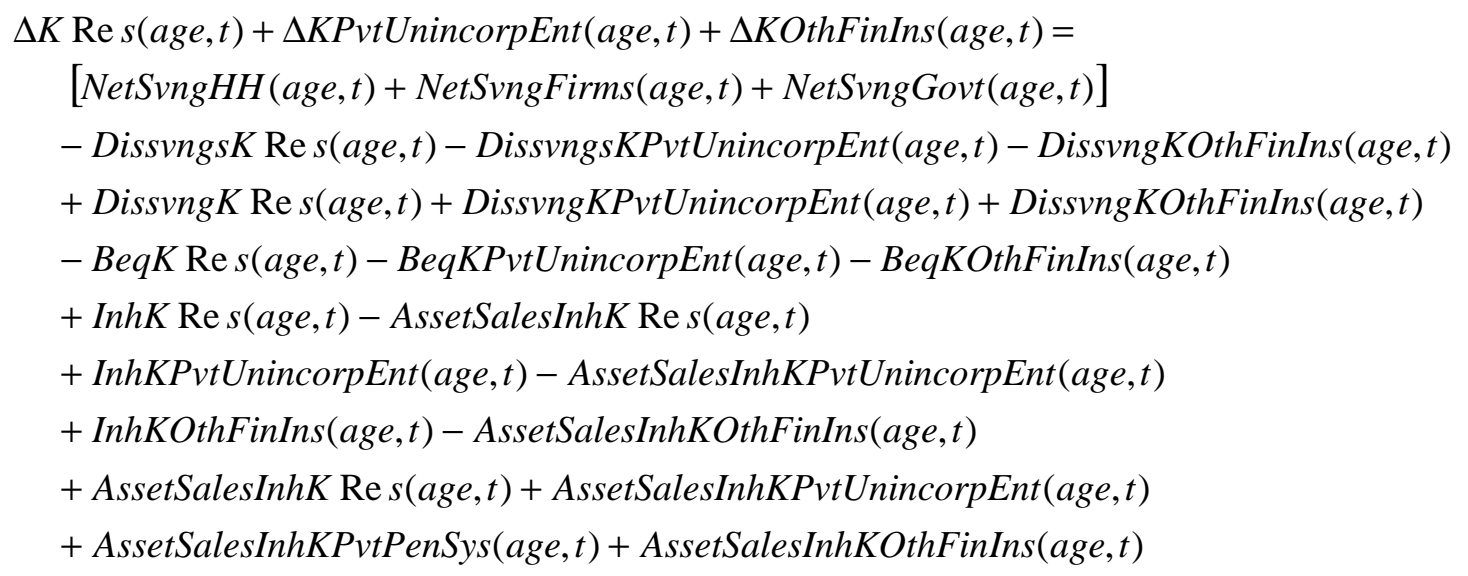

Cancellations bring us to

$\Delta K \operatorname{Re} s($ age,$t)+\Delta K P v t$ UnincorpEnt $($ age,$t)+\Delta K O \operatorname{HinFins}($ age,$t)=$

$[$ NetSvngHH $($ age,$t)+\operatorname{NetSvngFirms}($ age,$t)+\operatorname{NetSvngGovt}($ age,$t)]$

- BeqK Re $s($ age,t $t)-B e q K P v t U n i n c o r p E n t($ age,$t)-B e q K O t h F i n I n s($ age,$t)$

$+\operatorname{InhK} \operatorname{Re} s($ age,$t)+\operatorname{InhKPvtUnincorpEnt}($ age,$t)+\operatorname{InhKOthFinIns}($ age,$t)+\operatorname{InhKPvtPenSys}($ age,$t)$

Adding pension wealth,

$\Delta K \operatorname{Tot}($ age,$t)=$

$\Delta K P v t P e n S y s($ age,$t)+[$ NetSvngHH $($ age,$t)+\operatorname{NetSvngFirms}($ age,$t)+\operatorname{NetSvngGovt}($ age,$t)]$

- BeqK Re s(age,t) - BeqKPvtUnincorpEnt(age,t) - BeqKOthFinIns(age,t)

$+\operatorname{InhK} \operatorname{Re} s($ age, $t)+\operatorname{InhKPvtUnincorpEnt}($ age,$t)+\operatorname{InhKOthFinIns}($ age,$t)+\operatorname{InhKPvtPenSys}($ age,$t)$

Based on the definition of adjusted net household savings given above, NetSvngHH $($ age,$t)=\operatorname{AdjNetSvngHH}($ age,$t)-\Delta K P v t P e n S y s($ age,$t)-B e q K P v t P e n S y s($ age,$t)$

so

$\Delta K \operatorname{Tot}($ age,$t)=\Delta K P v t P e n S y s($ age,$t)$

$+\left[\begin{array}{c}\text { AdjNetSvgHH }(\text { age }, t)-\Delta K P v t P e n S y s(\text { age }, t)-B e q K P v t P e n S y s(\text { age }, t) \\ + \text { NetSvngFirms }(\text { age }, t)+\text { NetSvngGovt }(\text { age }, t)\end{array}\right]$

- BeqK Re s(age,t) - BeqKPvtUnincorpEnt(age,t) - BeqKOthFinIns(age,t)

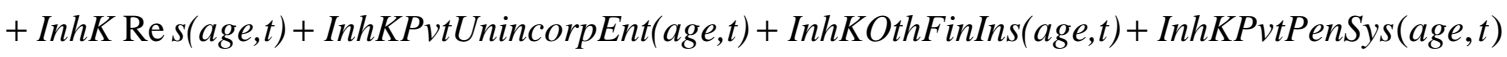

KPvtPenSys is cancelled out, leaving the result 


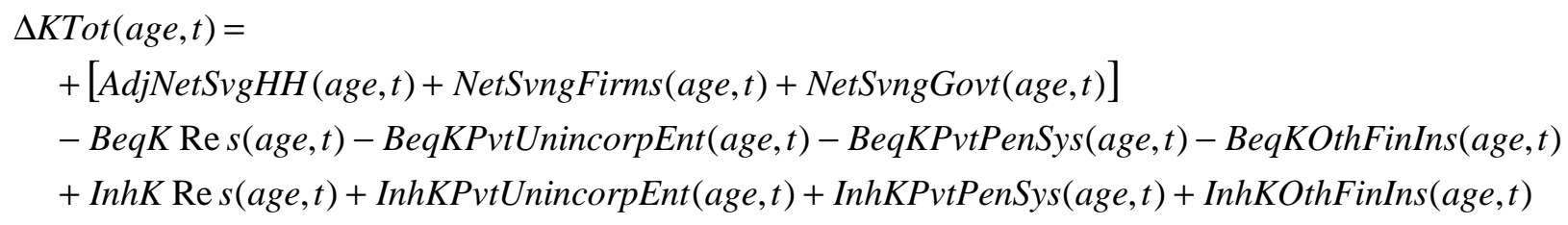

In other words, change in wealth for members of an age group in a given year is equal to their net saving, including net saving through the private pension system and their imputed share of the net savings of firms and government, plus the sum across all asset classes of inheritance minus bequests.

Summing over age groups, inheritance and bequests cancel out, leaving us with $\Delta \operatorname{KTot}(t)=\operatorname{AdjNetSvngHH}(t)+\operatorname{NetSvngFirms}(t)+\operatorname{NetSvngGovt}(t)$ 


\section{Annex 2: The Public Pension System (PubPenSys)}

\section{Expenditures}

The public pension system is assumed to be a defined benefit system financed on a Pay As You Go (PAYG) basis. Let

PubPenSysEnt (age,t, RetDur $), \operatorname{Re} t \operatorname{Dur}(t)=\overline{0: \operatorname{MaxAge}(t)-\operatorname{EligAge}(t)}$

be the social security benefit entitlement for the average person aged age who retired RetDur years ago, where EligAge is the age of eligibility for a pension and we assume PubPenSysEnt $($ age $, t, 0)=0$. The pension for persons entering retirement is computed according to the formula:

PubPenSysEnt $($ age $, t, 1)=$

$$
\operatorname{Re} \operatorname{plRate}(t) \sum_{j=1}^{a g e-15} \text { LabForcePartRate }(\operatorname{age}-j, t-j, 1) \frac{\left(\sum_{k=1}^{D} W(\text { age }-k, t-k)\right)}{\operatorname{Re} \operatorname{PPeriod}(t)}
$$

where we assume age $\geq$ EligAge and $l(r e g$, age $, t, 1)$, age $=\overline{15: \text { age }}$ is a sequence of agespecific labor force participation rates and $W$ is the age-specific wage rate. RefPeriod is the reference period over which past age-specific wages are averaged to compute the reference wage employed in calculation of the initial pension and ReplRate is the replacement rate, i.e. the ratio of the pension to the reference wage. The first summation term on the right-hand side is the average lifetime years of labor force participation, computed as the sum of age-specific labor force participation rates. For example, if age $=70$ and $t=100$, we would have

$$
\begin{aligned}
& \sum_{j=1}^{\text {age }-15} \text { LabForcePartRate }(\text { age }-j, t-j, 1)= \\
& \text { LabForcePartRate }(69,99,1)+\text { LabForcePartRate }(68,98,1)+\ldots+\text { LabForcePartRate }(15,45,1)
\end{aligned}
$$


which gives average number of years spent in the labor force by members of the cohort who retire aged 70 in year 100. Assuming RefPeriod=10, the rest of the formula is

$$
\frac{\left(\sum_{k=1}^{D} W(\text { age }-k, t-k)\right)}{\operatorname{Re} f \operatorname{Period}(t)}=\frac{[W(69,99)+W(68,98)+\ldots+W(60,90)]}{10}
$$

which gives average wage over the last ten years for members of the cohort who retire aged 70 in year 100.

Once persons have retired, their pension is indexed to average wages. For people who were already retired at $(t-1)$, the pension is

$$
\begin{aligned}
& \text { PubPenSysEnt }(\text { age }, t, \operatorname{Re} t \text { Dur })= \\
& \qquad \text { PubPenSysEnt }(\text { age }-1, t-1, \operatorname{Re} t \text { Dur }-1)\left[1+\operatorname{IndexRate}(t) \frac{\overline{\text { Wage }}(t)}{\overline{\operatorname{Wage}}(t-1)}\right]
\end{aligned}
$$

where IndexRate is the rate of indexation of pensions to the average wage rate $\overline{\text { Wage }}(t)$ and $0 \leq$ IndexRate $\leq 1$.

Social security system benefits paid out by age group of recipient are equal to the age- and retirement-duration specific entitlement times the number of recipients:

$$
\text { PubPenSysBen }(\text { age }, t)=\sum_{\operatorname{Re} t \text { Dur }(t)=0}^{\text {MaxAge }(t)-\text { EligAge }(t)} \text { PubPysEnt }(\text { age }, t, \operatorname{Re} t \text { Dur }) \text { Pop }(\text { age }, t, \operatorname{Re} t \text { Dur })
$$

and system-wide expenditures are equal to the summation over age groups

$\operatorname{PubPenSysBen}(t)=\sum_{\text {age }=\operatorname{EligAge}(t)}^{\text {MaxAge }(t)} \operatorname{PubPenSysBen}(\operatorname{age}, t) \operatorname{Pop}($ age,$t)$

For example, taking $t=10$, EligAge $=65$, and MaxAge $=100$ 


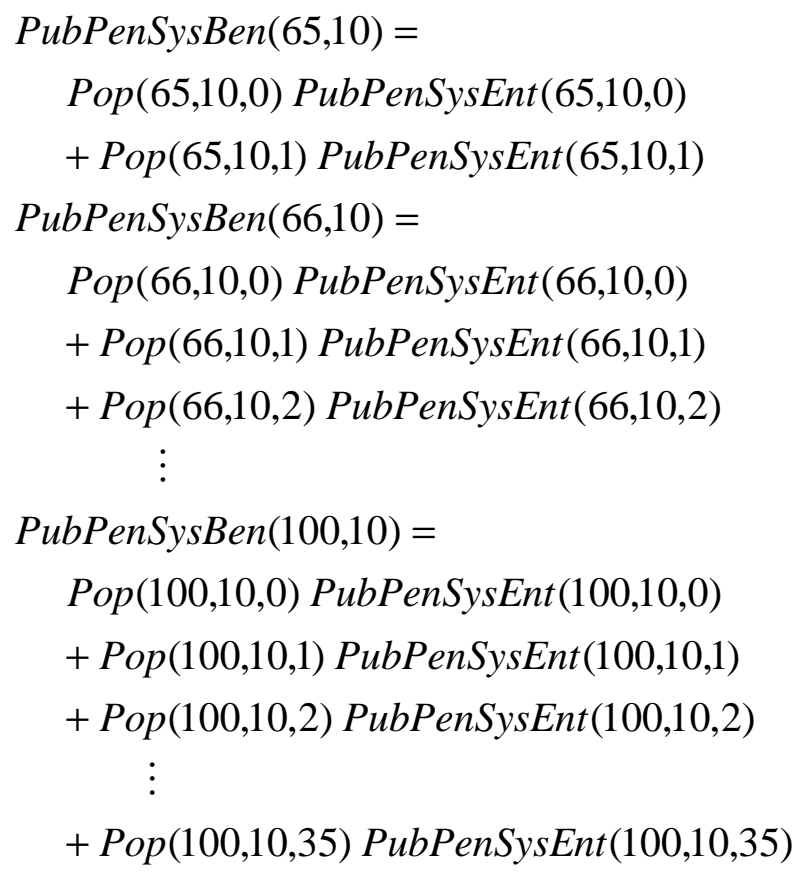

and

PubPenSysBen $(10)=$ PubPenSysBen $(65,10)$

+ PubPenSysBen $(66,10)+\cdots+$ PubPenSysBen $(100,10)$

\section{Revenues}

Contributions to the public pension system out of wages are

PubPenSysContWageY $(t)=\sum_{\text {age }=15}^{\text {Maxage }(t)}$ PubPenSysContRate $(t) \operatorname{WageY}(\operatorname{age}, t)$,

and out of entrepreneurial income are

PubPenSysContEntrY $(t)=\sum_{a g e=15}^{\text {Maxage }(t)}$ PubPenSysContRate $(t) \operatorname{Entr} Y($ age,$t)$

The social security contribution rate is assumed to be equal for all types of income and is independent of the age of the contributor. No distinction is made, in the case of contributions out of wage income, between employees' and employers' contributions. 
Total public pension system contributions are the summation over wages and entrepreneurial income:

PubPenSysCont $(t)=$ PubPenSysContWageY $(t)+\operatorname{PubPenSysContEntrY}(t)$

In the classic PAYG system design (for example, the German system), total contributions equal total benefits; there is neither accumulation of a surplus nor a deficit to be financed out of general government revenue. The default model solution option is one in which the required contribution rate is calculated by setting contributions equal to expenditures.

However, there are cases (for example, the USA), where nominally PAYG systems are currently running surpluses in order to accumulate resources to deal with the retirement of the baby boom generation. In other cases, deficits in the PAYG pension system are covered out of general tax revenue. To cover such cases, an alternative solution option is to set the contribution rate independent of benefits, in which case the model solves for the implied surplus or deficit. The balance of the social security system, say in year $\mathrm{T}$, is then given by:

$$
\begin{aligned}
& \text { PubPensSysBal }(T)=\text { PubPenSysCont }(T)-\text { PubPensSysExp }(T) \\
& \quad+r(T-1) \sum_{t=0}^{T-1} \text { PubPensSysBal }(T)
\end{aligned}
$$

In the event of an unreasonable deficit in the social security system, assumptions on retirement age and benefit calculation must be examined. 